\title{
Become more optimistic by imagining a best possible self: effects of a two week intervention
}

Citation for published version (APA):

Meevissen, Y. M. C., Peters, M. L., \& Alberts, H. J. E. M. (2011). Become more optimistic by imagining a best possible self: effects of a two week intervention. Journal of Behavior Therapy and Experimental Psychiatry, 42(3), 371-378. https://doi.org/10.1016/j.jbtep.2011.02.012

Document status and date:

Published: 01/09/2011

DOI:

10.1016/j.jbtep.2011.02.012

Document Version:

Publisher's PDF, also known as Version of record

Document license:

Taverne

Please check the document version of this publication:

- A submitted manuscript is the version of the article upon submission and before peer-review. There can be important differences between the submitted version and the official published version of record.

People interested in the research are advised to contact the author for the final version of the publication, or visit the DOI to the publisher's website.

- The final author version and the galley proof are versions of the publication after peer review.

- The final published version features the final layout of the paper including the volume, issue and page numbers.

Link to publication

\footnotetext{
General rights rights.

- You may freely distribute the URL identifying the publication in the public portal. please follow below link for the End User Agreement:

www.umlib.nl/taverne-license

Take down policy

If you believe that this document breaches copyright please contact us at:

repository@maastrichtuniversity.nl

providing details and we will investigate your claim.
}

Copyright and moral rights for the publications made accessible in the public portal are retained by the authors and/or other copyright owners and it is a condition of accessing publications that users recognise and abide by the legal requirements associated with these

- Users may download and print one copy of any publication from the public portal for the purpose of private study or research.

- You may not further distribute the material or use it for any profit-making activity or commercial gain

If the publication is distributed under the terms of Article $25 \mathrm{fa}$ of the Dutch Copyright Act, indicated by the "Taverne" license above, 


\title{
Become more optimistic by imagining a best possible self: Effects of a two week intervention
}

\author{
Yvo M.C. Meevissen*, Madelon L. Peters, Hugo J.E.M. Alberts \\ Clinical Psychological Science, Maastricht University, P.O. Box 616, 6200 MD Maastricht, The Netherlands
}

\section{A R T I C L E I N F O}

\section{Article history:}

Received 18 October 2010

Received in revised form

11 February 2011

Accepted 22 February 2011

\section{Keywords:}

Optimism

Intervention

Best possible self

Mood

\begin{abstract}
A B S T R A C T
Background and objectives: Optimism is a personality trait which has repeatedly been shown to correlate with, and predict psychological and physical well-being. The present study investigated whether optimism can be increased by imagining a best possible self (BPS). Effects were compared to a control group in which participants imagined their daily activities (DA).

Methods: In order to minimize inter-individual differences in content of imagery, participants constructed their BPS according to 3 domains, namely a personal, relational, and professional domain. All participants were instructed to practice their imagery exercise for 5 min per day over a period of two weeks. Effects on optimism and mood were measured after one session, after one week and after two weeks.

Results: Results indicated that BPS imagery led to significantly larger increases in optimism as compared to DA imagery, after one session and over a two week period. Effects on optimism remained after controlling for possible mediation by the change in positive mood.

Limitations: In order to test the effectiveness of our BPS imagery intervention we relied exclusively on self-report measures.

Conclusion: The present study confirmed that imagining a BPS enhances levels of optimism, independent of the mood effect.
\end{abstract}

(c) 2011 Elsevier Ltd. All rights reserved.

\section{Introduction}

Over the last 30 years, research in the field of optimism and pessimism has been expanding exponentially. Over this period, many cross-sectional and longitudinal studies have indicated that optimism correlates with and predicts psychological as well as physical well-being, both in the presence and absence of stressors (Scheier \& Carver, 1986, 1992). Optimism has been shown to correlate with higher levels of self-esteem (Lyubomirsky, Tkach, \& Dimatteo, 2006), positive mood (Andersson, 1996; Ben-Zur, 2002; Räikkönen, Matthews, Flory, Owens, \& Gump, 1999; Wenglert \& Rosen, 1995), more resilience to stressful or negative events (Solberg, Segerstrom, \& Septhon, 2005), self-mastery (Andersson, 1996), active coping (Andersson, 1996; Carver \& Scheier, 1999), prevention and stagnation of illnesses (Kivimäki et al., 2005; Matthews, Raikkonen, Sutton-Tyrell, \& Kuller, 2004), and recovery from illnesses, injuries, various types of surgery, and major lifeevents (Kivimäki et al., 2005; Mahler \& Kulik, 2000; Peters et al., 2007; Scheier \& Carver, 1986; Scheier et al., 1999). Although some

\footnotetext{
* Corresponding author. Tel.: +3164933 6788.

E-mail address: Yvo.Meevissen@maastrichtuniversity.nl (Y.M.C. Meevissen).
}

studies have revealed less desirable correlates, for example reduced health-protective behaviors (Tennen \& Affleck, 1987; Weinstein \& Lyon, 1999), more positive expectations and continued gambling despite negative gaming outcomes (Gibson \& Sanbonmatsu, 2004), and lower immune responses under high challenge conditions (Segerstrom, 2005, 2006), the benefits of optimism seem to outweigh the potential downsides.

Optimism is generally considered to be a personality trait. The most well-known conceptualization is provided by Scheier and Carver (1982) who defined optimism as a general and global positive expectancy of the future. Peterson et al. (1982) defined optimism in terms of explanatory style. According to this conceptualization optimists attribute negative events to external factors, and as being temporal/unstable and local, whereas pessimists attribute negative events to internal factors, and consider these as long-lasting/stable and global. For positive events, the reverse pattern of attribution styles is found for optimists and pessimists. By employing an optimistic explanatory style, negative situations become deflated and less significant in determining future cognition and behavior whereas positive situations become inflated and more significant in determining future cognition and behavior. Although many studies conducted so far, deliver converging evidence of optimism being related to desirable psychological and 
physical factors, most of them utilize cross-sectional or longitudinal correlational designs. This makes it impossible to ascertain whether optimism is actually a cause for these desirable factors, a result from them or whether both are dependent on a third factor. In order to investigate and establish the causal relationships between optimism and various beneficial outcomes, controlled experiments, in which optimism is directly manipulated, are needed. This necessary development in research plus the positive contributions optimism may entail in the clinical setting, indicates the relevance of developing and testing optimism increasing interventions. Previous optimism interventions have mainly focused on changing explanatory style of past events and not directly on changing future expectancies (Fresco, Moore, Walt, \& Craighead, 2009; Riskind, Sarampote, \& Mercier, 1996; Ruthig, Perry, Hall, \& Hladkyj, 2004; Seligman, 1998). Only recently have researchers begun to search for an intervention tool that directly targets optimism-related cognitions (Fosnaugh, Geers, \& Wellman; 2009; Peters, Flink, Boersma, \& Linton, 2010). Fosnaugh, Geers, and Wellman (2009) used two different manipulations, a direct method consisting of generating thoughts about the future and an indirect method consisting of a semantic priming task. Both manipulations led to moderate increases in generalized optimism immediately afterward.

Peters et al. (2010) used the so called "best possible self" (BPS) manipulation, a positive future thinking technique based on the work of King (2001). A BPS requires people to envision themselves in an imaginary future in which everything has turned out in the most optimal way. Over the past years, writing about and imagining a BPS has repeatedly been demonstrated to increase people's mood and well-being (King, 2001; Peters et al., 2010; Sheldon \& Lyubomirsky, 2006). Peters et al. (2010) provided evidence that writing about and imagining a BPS can also increase optimism in terms of expecting favorable outcomes. This effect was independent from the effect on mood that was simultaneously increased by the manipulation. However, only the immediate post-manipulation effects were studied, and it cannot be excluded that the effects were only transient with little influence on related cognitions and behaviors. The current study therefore investigated whether daily BPS exercises are effective in boosting optimism over a period of two weeks. Since numerous studies have indicated that a positive future expectancy as well as an optimistic explanatory style may be beneficial for one's personal well-being, the present study measured optimism both in terms of future expectancy and explanatory style. Although the BPS technique most directly targets positive future expectancies, considering Fredrickson's (2001) broaden-and-build model, in time the BPS imagery exercise could generalize to optimistic explanatory style.

A secondary aim was to examine who may profit most from a BPS intervention. In previous studies (Harrist, Carlozzi, McGovern, \& Harrist, 2007; Peters et al., 2010) effects of BPS imagery were not moderated by dispositional optimism. These findings are counterintuitive since it is reasonable to expect that people who are low in optimism benefit more from an optimism induction as compared to people high in optimism, mainly because of their larger potential to gain in optimism. Therefore, the present study re-examined the moderation effect by dispositional optimism. In addition, we examined whether intervention effects were moderated by motivation. A previous study by Sheldon and Lyubomirsky (2006) found that intrinsic motivation to comply with their daily visualization exercises predicted participants' frequency of visualization and self-reported visualization performance, outcomes which are likely to increase the intervention effect.

In sum, we hypothesized that a BPS imagery intervention would not only increase immediate post-manipulation future expectancies, but after a two week repeated sessions intervention it would also be able to enhance cognitions that are considered to be more stable like general future expectancy and explanatory style. Furthermore, we expected the effect of optimism to be independent of any effects on mood that the intervention might additionally have and to be more effective in low dispositional optimists and in highly motivated participants.

\section{Methods}

\subsection{Participants}

In the present study we adopted a repeated measures split-plot design with an experimental condition and a control condition. A total of 54 native Dutch-speaking participants with ages ranging from 18 to $43(M=23.5, S D=6.39)$ were randomly divided over both conditions ( $n=28$ in the experimental condition, $n=26$ in the control condition). Most participants were students from the faculty of psychology and neuroscience and the faculty of medicine, health, and life science of Maastricht University. Since females are overrepresented at these faculties the total pool consisted of 50 female and 4 male participants. For the repeated sessions analyses, three female participants in the control group were excluded because they failed to complete the required mid-term or posttreatment questionnaires.

\subsection{Intervention}

Because various studies have indicated that imagery (or visualization) involves deeper cognitive processing as compared to verbalization or writing (Holmes, Arntz, \& Smucker, 2007; Holmes, Mathews, Mackintosh, \& Dalgleish, 2008) we chose imagery as a method to implement the BPS exercise. Participants were informed that they would be participating in a study in order to measure "the power of visualization". The experimental and control condition had the same format and only differed in the content of imagery, i.e. BPS in the experimental condition and daily activities (DA) in the control condition (cf. Sheldon \& Lyubomirsky, 2006). All participants received an instruction manual. Building on the study of King (2001), the instruction manual provided participants in both conditions with the following information:

This manual helps you step by step to improve your visualization skills. All information you provide in this manual is confidential. We therefore would like to emphasize that this manual at all times remains in your possession and will only be looked into and read by you.

After this introduction participants received the specific instructions appropriate for their respective condition (see Appendix A). In order to control for possible manipulation awareness participants in both conditions were told that the manipulation could induce positive mood (cf. Sheldon \& Lyubomirsky, 2006). In the BPS condition, participants were asked to think of and write down all aspects that their future best possible self should encompass. In order to standardize the imagery exercise as much as possible, while at the same time warranting the freedom to imagine content which is most relevant to the participant, we provided three broad domains: a personal domain, a relational domain and a professional domain. These domains were selected based on the consideration that these areas are most influential and significant in determining people's well-being (e.g. Argyle, 2001). Moreover, participants were instructed to formulate their BPS by starting each sentence with "In the future I will", first to encourage them to construct realistic and attainable goals and second to guarantee a focus on the positive rather than on the negative discrepancy of a current self not having reached its desired state or full potential. In the control condition participants were asked to think of and write down all the activities 
that had taken place during the last $24 \mathrm{~h}$ and to reflect on their thoughts and mood during those activities. Next, in both conditions participants were requested to write a personal story in which they put together their earlier statements in a detailed and coherent story. Finally, they performed a 5-min imagery exercise in which they imagined their previously written BPS story (experimental condition) or their daily activities during the past $24 \mathrm{~h}$ (control condition). All participants were instructed to repeat this 5-min imagery exercise once a day at home over the next two weeks.

\subsection{Measures}

\subsubsection{Optimism}

Dispositional optimism was measured using a Dutch translation of Scheier and Carver's (1985) Life Orientation Test (LOT), which reflects the extent to which individuals generally expect favorable outcomes. The LOT consists of 12 statements of which 4 are positively stated, 4 are negatively stated, and 4 are filler items. All items are rated along a 5-point continuum (0: strongly disagree -4 : strongly agree). A total LOT score can be obtained by summation of the scores on the 4 positively phrased items and the reversed scores of the 4 negatively phrased items, higher scores reflecting higher levels of optimism. In the present sample, an internal consistency of .81 was obtained.

The subjective Probability task (SPT; MacLeod, 1996) was used as a measure of more specific positive and negative future expectancies. The SPT consists of 20 statements referring to negative expectancies (SPT-neg e.g. "you will have health problems") and 10 statements referring to positive expectancies (SPT-pos e.g. "people will admire you"). Participants are asked to judge the likelihood that they will experience these specific outcomes on a 7-point scale (not at all likely to occur - extremely likely to occur). Higher scores on this scale represent a higher estimated likelihood of positive or negative future events. In the present study, Cronbach's alphas of .82 for the positively stated items and .91 for the negatively stated items were obtained. A previous study demonstrated the SPT to be sensitive to a brief optimism manipulation (Peters et al., 2010).

Optimistic explanatory style was measured using a Dutch version of the Attributional Style Questionnaire (ASQ) (Seligman, Abramson, Semmel, \& von Baeyer, 1979; Dutch version: Cohen, van den Bout, Kramer, \& Vliet, 1986). The ASQ consists of 12 hypothetical events, 6 good (e.g. You meet a friend who compliments you on your appearance) and 6 bad (You have been looking for a job unsuccessfully for some time). For each event, participants are asked to write down the one major cause of each event, imagining this event would occur to them. The hypothetical cause is then rated on a 7-point scale for three causal dimensions: 1. internal versus external (Totally due to other people or circumstance - Totally due to me), 2. stable versus unstable (Will never again be present - Will always be present), and 3. global versus local (Influences just this particular situation - Influences all situations in my life). A total ASQ score is obtained by averaging the scores over all three dimensions per event, and calculating a grand average of scores on the positively stated items and the reverse scores on the negatively stated items. The ASQ takes on average 15 min to complete. Higher scores on this scale represent a more optimistic attribution style. In the present study, a Cronbach's alpha of .81 was obtained.

\subsubsection{Affect}

In order to measure affect, a Dutch version of the shortened Positive and Negative Affect Scale (PANAS; Mackinnon et al., 1999) was used. The shortened version of the PANAS consists of 5 items describing positive affective states (PA) and 5 items describing negative affective states (NA). Participants rate on a five-point scale to what extent they feel a particular affective state is present (Not at all - Extremely). In order to measure trait and state affect three different versions of the PANAS were used. For baseline measurement a version inquiring about the frequency of affective states during the past year was used. At one and two weeks postintervention a version inquiring about the frequency of affective states during the past week was used. To assess the immediate effects of the intervention during the lab session a version inquiring about the intensity of affective states at this moment was used. Higher scores on the PA scale reflect higher levels of positive mood while higher scores on the NA scale reflect higher levels of negative mood. In the present study Cronbach's alphas for the three PANAS versions ranged from .71 to .77 for PA and .86 to .89 for NA.

\subsubsection{Neuroticism}

Neuroticism was measured by the Dutch version of the Neuroticism scale of the Eysenck Personality Questionnaire (EPQN; Eysenck, Eysenck, \& Barrett, 1985; Eysenck \& Eysenck, 1994). The EPQ-N scale used in the current study is the shortened version consisting of twelve items (Birley et al., 2006) describing different affective states which are indicative of neuroticism. Participants are required to indicate whether a particular state applies to them (yes/ no) with higher scores reflecting higher levels of neuroticism. The present study revealed a Cronbach's Alpha of .79.

\subsubsection{Manipulation $\mathcal{E}$ control checks}

In order to obtain more insight into the effectiveness of the intervention and to control for inter-personal differences, participants filled out questions on the difficulty of the imagery exercise and the ease of implementing imagery exercises, both rated on a 5point scale ranging from "easy" to "difficult". Moreover, we measured the frequency of applying the imagery exercise (number of sessions per week), changes in imagery skill over the past two weeks (5-point scale: "improved a lot" - "deteriorated a lot"), content of imagery and awareness of the purpose of the imagery exercise. Answers to the latter question were categorized as unaware, aware of positivity induction and aware of optimism induction. Finally, we included the Self-Concordance Motivation (SCM) questionnaire (Sheldon \& Elliot, 1999) which was found to correlate with participants' frequency of practicing a daily imagery exercise and with self-reported imagery performance (Sheldon \& Lyubomirsky, 2006). The SCM comprises one or several goal statements which in the present study implied practicing imagery ("I will engage in the imagery practice on a daily basis for the following reasons"). This goal is evaluated on 4 different motivational levels, ranging from extrinsic to intrinsic, and rated on a 9point scale ranging from 1 "not at all for this reason" to 9 "completely for this reason". A total score is obtained by subtracting the two extrinsic motivation scores from the two intrinsic motivation scores, higher scores reflecting more intrinsic motivation.

\subsection{Procedure}

Three days before the first lab session, participants received the PANAS, LOT, ASQ and EPQ-N by e-mail. These questionnaires had to be filled out and returned before the first lab session. The lab sessions took place at the university in a dedicated room for behavioral experiments. After giving instructions, the experimenter left the lab in order to let the participant work on the tasks without being distracted or disturbed. Contact could be established through an intercom. First, the SPT and PANAS were completed. After a 15min delay in which participants carried out a behavioral task (results not reported), the experimenter returned and presented 
the participant with either the BPS or the DA imagery manual. From hereon, all instructions were audio taped and presented through headphones to guarantee standardization and facilitate concentration during imagery by preventing disturbances by environmental noise.

First, all participants received a 5 min imagery training during which they imagined a lemon using all their senses (cf. Holmes, Coughtrey, \& Connor, 2008). This training familiarized participants with imagery and clarified the importance of focusing on the subjective feelings and emotions this evoked. Next, all participants prepared their daily imagery exercise by following the instructions in their manual. After 20 min of writing about their BPS or DA they performed the 5-min imagery exercise. Upon completion, participants filled out the state PANAS and the SPT once more to assess the immediate effects of the writing and imagery exercise. In order to minimize repetition effects, two versions of the PANAS and the SPT were constructed by means of item randomization and presented counterbalanced to control for possible version effects. At the end of the first lab session participants were instructed to practice the imagery exercise at home once a day for 5 min over a period of two weeks. Finally, the SCM was administered.

After one and two weeks participants again filled out the LOT, SPT, and PANAS. Because of its length, the ASQ was only readministered after two weeks. All questionnaires were sent by email, except for the final SPT and PANAS which, for consistency reasons, were administered during the post-treatment lab session. In this session, participants also filled out the manipulation and control check questionnaire, were debriefed and received a gift certificate of 25 Euro.

\subsection{Data analyses}

The immediate effects of the imagery during the first lab session were examined using analyses of covariance (ANCOVA) with condition as the between-subject factor and post-manipulation perceived probability of positive events (SPT-pos), perceived probability of negative events (SPT-neg), positive affect (PA) and negative affect (NA) as the dependent variables, and their respective pre-intervention scores as the covariate.

Because we expected that the BPS intervention would specifically affect our measures of optimism (LOT, SPT-pos, SPT-neg and ASQ) and positive affect, but not negative affect and neuroticism, we first performed two omnibus (multivariate) tests. The first multivariate analysis of variance (MANOVA) tested differences between conditions on the change scores (post-treatment score minus baseline score) in LOT, SPT-pos, SPT-neg, ASQ and PA; the second MANOVA tested differences between conditions on the change scores in NA and EPQ-N. Next, 2 (condition) $\times 2$ (time) ANCOVAs for repeated measures were used to test between condition differences after one and two weeks of intervention for each outcome separately using the respective pre-intervention score as the covariate. Since explanatory style (ASQ) was only measured twice (pre-intervention and post-treatment), univariate ANCOVA was used for this variable. The main analyses were followed up by post hoc repeated measures ANOVAs within conditions to further explore the direction and timing of the intervention effects.

To assess whether the changes in optimism could have been mediated by the effect of the intervention on positive affect, we repeated the $2 \times 2$ ANCOVA for repeated measures on changes in dispositional optimism (LOT) with condition as independent variable, and baseline optimism and change in positive affect as covariates. Mediation by positive affect is indicated by a condition effect becoming non-significant.

In order to test whether the effects of the intervention were moderated by dispositional optimism we dichotomized participants by a median split on their pre-intervention optimism scores. Next the dichotomized optimism score was added as an additional between-subject factor to the ANCOVAs. Moderation is indicated by a significant condition $\times$ pre-intervention optimism interaction term (Baron \& Kenny, 1986). The same procedure was used to investigate whether intrinsic motivation ( $\mathrm{SCM}$ ) moderated the intervention effect.

All analyses were performed using PASW Statistics 18.0 for Windows.

\section{Results}

\subsection{Baseline descriptives}

An independent samples $t$-test on baseline scores between conditions revealed no significant differences between conditions on any of the measures, indicating that randomization was successful and motivation to carry out the daily imagery exercise was equal in both conditions. An independent samples $t$-test revealed no significant differences between the two versions of the PANAS and SPT (both administered during the first lab session).

Table 1 shows the mean scores and correlations of baseline scores on the LOT, SPT positive outcome (SPT-pos), SPT negative outcome (SPT-neg), trait PANAS positive affect (PA), trait PANAS negative affect (NA), and ASQ. Most correlations were in the expected direction. In line with previous findings (Gordon, 2008; Reilley, Geers, Lindsay, Deronde, \& Dember, 2005), the ASQ did not significantly correlate with the LOT or the SPT, indicating that explanatory style pertaining to past events may be unrelated to expectancies of future events. Moreover, whereas the LOT and SPTpos correlated negatively with negative affect, ASQ showed a positive correlation.

\subsection{Intervention effects}

Single-session effects replicated previous findings by Peters et al. (2010) namely significant condition effects for SPT-pos ( $F[1$, $\left.51]=14.96, p<.01, \eta_{\rho}^{2}=.23\right)$, SPT-neg $(F[1,51]=10.92, p<.01$, $\left.\eta_{\rho}{ }^{2}=.18\right)$ and PA $\left(F[1,51]=16.10, p<.01, \eta_{\rho}{ }^{2}=.24\right)$ reflecting larger increases on SPT-pos and PA and larger decreases on SPT-neg after writing and visualizing a BPS as compared to writing and visualizing DA (Table 2).

The omnibus MANOVA on the post-treatment change scores in LOT, SPT-pos, SPT-neg, PA, and ASQ as multivariate dependent variables indicated a significant condition effect $(F[5,46]=5.72, p<.01$, $\left.\eta_{\rho}^{2}=.286\right)$. As expected, there was no significant condition effect for the MANOVA on post-treatment change scores in NA and EPQ-N ( $F$ $\left.[2,49]=.55, p=.580, \eta_{\rho}{ }^{2}=.022\right)$. The ANCOVAs on the baseline corrected mid-term and post-treatment scores for the individual dependent variables yielded significant condition effects for the LOT $\left(F[1,50]=5.86, p=.019, \eta_{\rho}^{2}=.109\right), \operatorname{SPT}-\operatorname{neg}(F[1,50]=6.46, p=.014$,

Table 1

Descriptive data and intercorrelations between questionnaires at baseline.

\begin{tabular}{|c|c|c|c|c|c|c|c|}
\hline \multirow[b]{2}{*}{ Scales } & \multicolumn{2}{|l|}{ Descriptives } & \multicolumn{5}{|c|}{ Correlations } \\
\hline & Mean (SD) & Range & 1 & 2 & 3 & 4 & 5 \\
\hline 1. LOT & $21.63(5.09)$ & $6-31$ & & & & & \\
\hline 2. SPT-pos & $4.89(.67)$ & $2.9-6.4$ & $.555^{\mathrm{b}}$ & & & & \\
\hline 3. SPT-neg & $2.98(.82)$ & $1.4-4.9$ & $-.302^{\mathrm{a}}$ & -.193 & & & \\
\hline 3. PANAS-PA & $3.41(.64)$ & $2.2-5.0$ & .237 & $.536^{\mathrm{b}}$ & .171 & & \\
\hline 4. PANAS-NA & $2.11(.81)$ & $1.0-3.8$ & $-.365^{b}$ & $-.313^{a}$ & $.295^{\mathrm{a}}$ & .016 & \\
\hline 5. ASQ & $4.44(.40)$ & $3.7-5.3$ & .033 & .236 & -.088 & -.024 & $.320^{\mathrm{a}}$ \\
\hline 6. SCM & $6.22(4.77)$ & -8.0 to 16.0 & & & & & \\
\hline
\end{tabular}

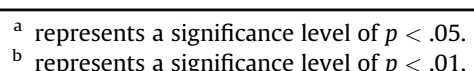


Table 2

Mean and SD scores on questionnaires before and after a single imagery session by exercise condition.

\begin{tabular}{|c|c|c|c|c|}
\hline & \multicolumn{2}{|l|}{ Best possible self } & \multicolumn{2}{|l|}{ Daily activities } \\
\hline & Pre-intervention mean (SD) & Post-intervention mean (SD) & Pre-intervention mean (SD) & Post-interventi on mean (SD) \\
\hline SPT-pos & $4.84(.73)$ & $5.28(.68)$ & $4.95(.62)$ & $4.89(.80)$ \\
\hline SPT-neg & $2.79(.72)$ & $2.18(.59)$ & $3.19(.72)$ & $2.90(.96)$ \\
\hline PANAS-PA & $2.86(.48)$ & $3.35(.66)$ & $2.62(.75)$ & $2.55(.75)$ \\
\hline PANAS-NA & $1.17(.22)$ & $1.14(.50)$ & $1.34(.65)$ & $1.23(.48)$ \\
\hline
\end{tabular}

$\left.\eta_{\rho}^{2}=.119\right)$, and $\mathrm{PA}\left(F[1,50]=10.38, p<.01, \eta_{\rho}^{2}=.178\right)$. The condition effect for the SPT-pos $\left(F[1,50]=3.79, p=.057, \eta_{\rho}^{2}=.073\right)$ and the $\operatorname{ASQ}\left(F[1,52]=3.16, p=.082, \eta_{\rho}^{2}=.061\right)$ only showed a trend toward significance. As expected, no condition effects were found for either $\mathrm{NA}\left(F[1,50]=.84, p=.773, \eta_{\rho}{ }^{2}=.002\right)$ or EPQ-N $(F[1,50]<.001$, $\left.p=.997, \eta_{\rho}{ }^{2}=.073\right)$.

Post hoc analyses within conditions indicated that participants in the BPS condition showed significant increases from baseline to mid-term and post-treatment in their scores on the LOT, SPT-pos and ASQ and decreases in their scores on the SPT-neg and NA. PA and EPQ-N remained unchanged. Participants in the control condition did not show significant changes in LOT, SPT-pos, SPT-neg or ASQ and EPQ-N, but unexpectedly DA imagery led to significant decreases in both NA and PA. To explore the timing of the BPS intervention effect, two contrasts (mid-term versus baseline and post-treatment versus baseline) were specified. The effects of the intervention on the SPT-neg, SPT-pos and NA were already significant after one week of BPS imagery, whereas for the LOT there was a non-significant trend $(p=.058)$ after one week. The effects are illustrated in Figs. $1-4$.

\subsection{Mediation of the effects on dispositional optimism by changes in positive affect}

To examine whether the increases in LOT after intervention were mediated by increases in positive affect, we repeated the ANCOVA for repeated measures analyses on LOT scores adding the difference score on positive affect as a covariate to the model. The effect of condition remained significant and with hardly any decrease in effect size $\left(F[1,50]=5.53, p=.023, \eta_{\rho}{ }^{2}=.105\right)$ indicating that the intervention effect on dispositional optimism was not mediated by changes in positive affect.

\subsection{Moderation of the intervention effects by trait optimism and intrinsic motivation}

To test whether the effects of the intervention were moderated by baseline dispositional optimism we categorized participants as

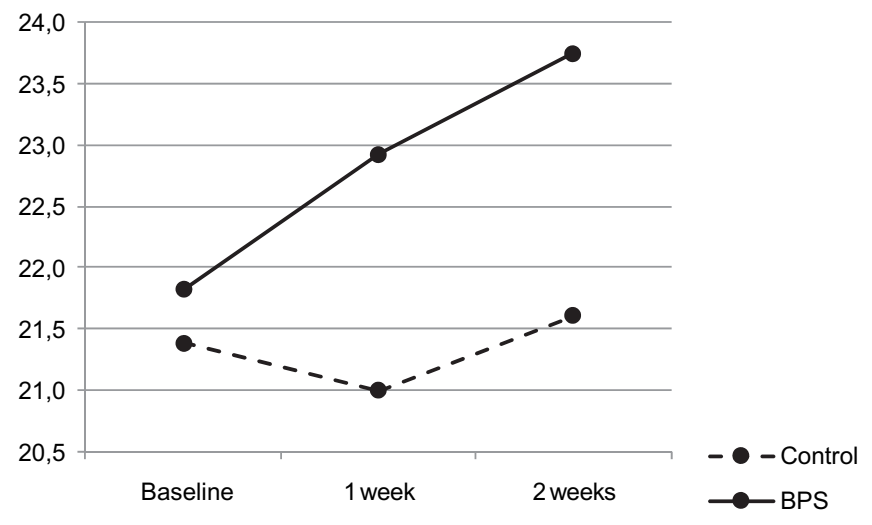

Fig. 1. Dispositional optimism as measured by the LOT at baseline, at mid-term (after 1 week), and post-intervention (after 2 weeks) per condition. either high $(n=26)$ or low $(n=25)$ on optimism based on a median split in their pre-intervention baseline scores. The same ANCOVAs as before were performed, but this time with optimism as an additional between-subject factor. None of the 2-week intervention effects were moderated by baseline optimism. We also tested whether levels of intrinsic motivation (SCM) moderated the intervention effect. This appeared not to be the case. Moreover, intrinsic motivation did not predict frequency of imagery practice nor subjective imagery performance.

\subsection{Post-intervention checks}

A t-test measuring differences between conditions revealed that participants in the experimental condition reported significantly less difficulty in performing the imagery exercise $(M=2.46$, $S D=1.04)$ as compared to the control condition $(M=3.13$, $S D=1.12)(t[50]=2.21, p=.031)$ and higher frequencies of practicing imagery indicated by the amount of sessions per week $(M=5.75, S D=.84$ in the experimental condition and $M=5.00$, $S D=1.14$ in the control condition, $t[50]=-2.72, p<.01)$. Because the difference in imagery performance and frequency of imagery between conditions may have affected the outcome, we carried out a post hoc moderation analyses for the differences in LOT, SPT, ASQ and PANAS scores between conditions with either imagery performance or frequency of practicing as the potential moderator. Neither imagery performance nor frequency of imagery appeared to have confounded the results.

\section{Discussion}

The present study tested the effectiveness of a best possible self (BPS) imagery intervention for increasing levels of optimism. Extending previous findings that writing about and imagining a BPS leads to an immediate increase in positive future expectancies and decrease in negative future expectancies (Peters et al., 2010) the present study showed that daily imagery of BPS for two weeks

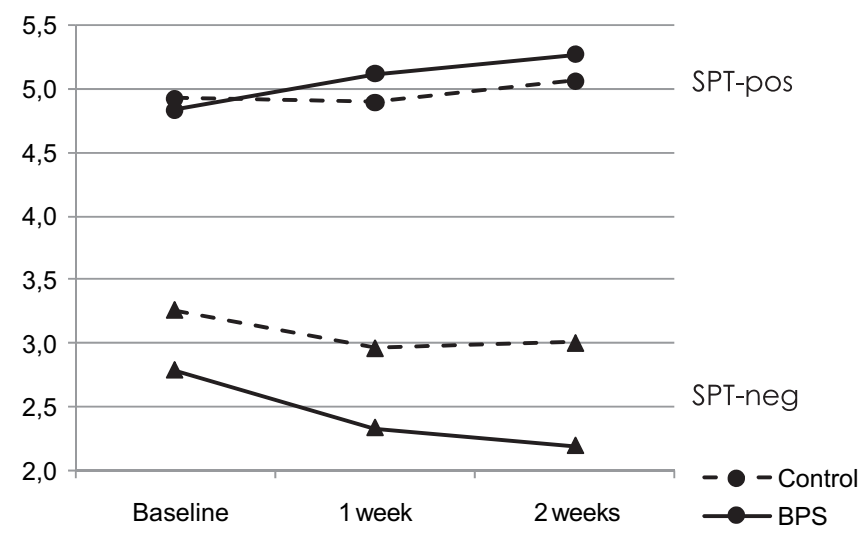

Fig. 2. Rated likelihood of positive future events (Pos Exp.) and negative future events (Neg Exp.) as measured by the SPT at baseline, at mid-term (after 1 week), and postintervention (after 2 weeks) per condition. 


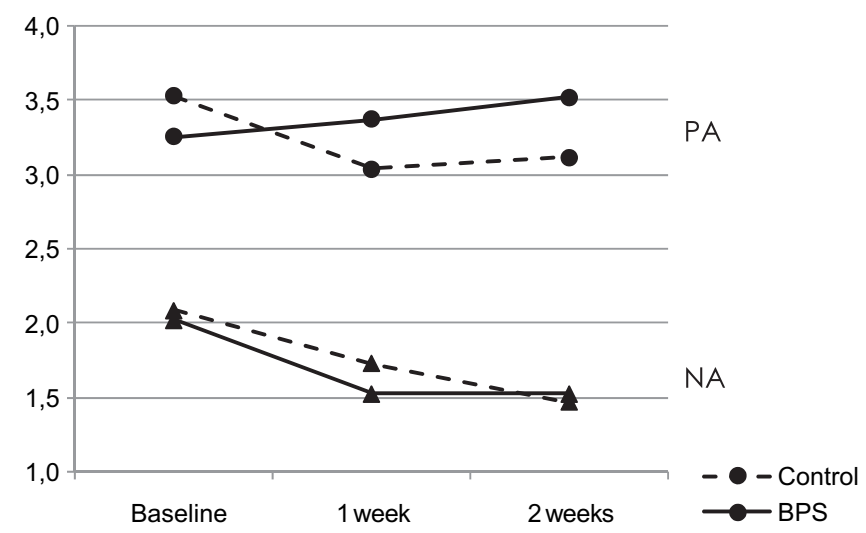

Fig. 3. Positive affect (PA) and negative affect (NA) as measured by the PANAS at baseline, at mid-term (after 1 week), and post-intervention (after 2 weeks) per condition.

can lead to sustained increases in optimism. Moreover, the effect on optimism remained after controlling for changes in positive affect. The results further demonstrated that initial levels of dispositional optimism did not moderate the intervention effects. People who were already high in optimism profited from the intervention to the same extend as participants low in optimism.

We chose daily imagery of a positive future scenario to boost levels of optimism. According to the expectancy -value model, progress toward a goal increases the confidence of a good outcome (Carver \& Scheier, 1999). Mental simulation of a positive scenario has been proposed to have the same effect as actual behavior and therefore may similarly lead to increased levels of confidence for success. Previously, visualization exercises have effectively been used to increase levels of self-esteem (Korrelboom, de Jong, Huijbrechts, \& Daansen, 2009). Interestingly, even though the BPS intervention primarily targeted positive expectancies, the effects seemed to generalize to optimistic explanatory style. Although the condition effect in the ANCOVA failed to reach significance, ASQ scores significantly increased after two weeks of BPS imagery but not after DA imagery. Moreover, whereas we found that in accordance with previous studies (e.g. Gordon, 2008; Peterson \& Vaidya, 2001) LOT and ASQ scores did not significantly correlate on baseline, after two weeks of BPS imagery - but not after daily activity imagery - the correlation between the two measures became significant and quite substantial (Pearson's $r=.55$ ). We propose that optimism may be part of a self-preserving and self-enhancing iterative mechanism similar to the broaden-and-build model described by Fredrickson (2001). An increase in positive expectancies may subsequently

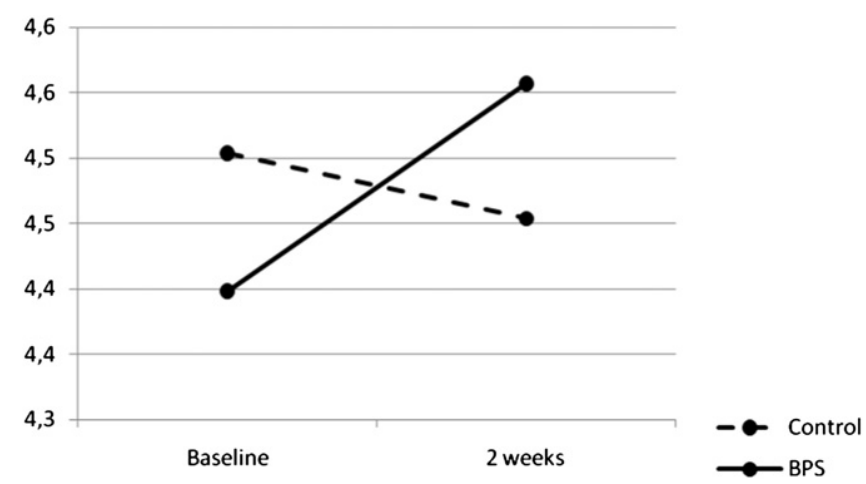

Fig. 4. Attribution style as measured by the ASQ at baseline and post-intervention (after 2 weeks) per condition. lead to reciprocal alterations and reinforcements of other positive cognitions and resources and thereby these resources may in time become more interrelated.

In the present study, dispositional optimism did not moderate the intervention effects. Nevertheless, one may question whether people already high in optimism profit as much from an additional increase in optimism in terms of physical and mental health benefits compared to participants starting out with a low level of optimism. In addition, the level of a priori motivation to carry out the imagery exercises and the frequency of imagery neither moderated the intervention effects. The latter finding may suggest that it is not necessary to practice imagery every single day, although it should be noted that the self-reported frequency was quite high (on average more than 5 times a week). In accordance with the proposed iterative mechanism, it may be that enhanced awareness of positive expectations and application of these cognitions in daily life is equally or maybe even more important in maintaining or enhancing dispositional optimism. In addition, it should be pointed out that the BPS imagery exercise was considered less difficult and was carried out more often as compared to the DA imagery exercise. This finding indicates the potential of a BPS imagery exercise as a feasible application in daily life.

Some limitations of the study should be mentioned. First, our participants predominantly consisted of well-educated young women. Although gender differences in BPS imagination skills are unlikely, women may be more receptive to an imagery exercise, which might have increased the intervention effect. Moreover, imagining yourself in the future in the best possible circumstances may be much easier for younger people since they still have the time and potential to work up to their BPS in a distant future and for well educated people who in general perceive more opportunities in life. Results from the present study can therefore not be generalized to the general population and future studies may test the appropriateness of this intervention in different populations.

Second, although imagery as an implementation method to bring about cognitive changes has several advantages over writing or talking, it also has drawbacks. To begin with the advantages, imagery leads to deeper cognitive processing and using mental imagery rather than words, overcomes potential difficulties or inter-personal differences in the ability to verbalize thoughts and images. Moreover, on a practical level mental imagery is less time consuming and requires fewer resources. However, the downside of imagery from an experimental point of view is that there is little control over the imagery content and practice. In the present study we tried to control and reduce the inter-individual differences by providing the participant with clear and structured instructions for composing their BPS or daily activities. Nevertheless, future research should attempt to gain more insight in the specific content being imagined by the participant.

Third, because of the exclusive reliance on self-report instruments we cannot rule out the possibility that demand effects may have influenced the results. We tried to minimize demand by informing participants in both conditions that the imagery exercises may have mood enhancing effects. Nevertheless, developing and including measures that are more indirect and therefore less susceptible to potential demand characteristics would be an important next step in future research. In addition, in order to find further support for our proposed iterative mechanism of optimism, it would be interesting to see how effects develop after cessation of BPS imagery. Perhaps continued imagery practice is not necessary in order to maintain or enhance the effects. Future research should therefore include additional follow-up assessments.

Finally, although we demonstrated that BPS imagery can successfully boost levels of optimism effect sizes were small to moderate. It remains to be determined whether an optimism 
intervention like the one used in this study can also improve optimism-related cognitions and behaviors, like less biased cognitive processing (Segerstrom, 2001), productive persistence in the face of set-backs (Scheier \& Carver, 1982), active coping (e.g. Carver \& Scheier, 1999), or even health benefits (e.g. Kivimäki et al., 2005). The inclusion of a broader range of outcome measures could first of all establish a better understanding of causality and second of all give more insight in the potential span of the beneficial effects of a BPS intervention.

In conclusion, the present study indicated that daily imagery of a best possible self (BPS) over a period of two weeks caused significantly larger improvements in levels of optimism as compared to imagery of daily activities. The current BPS imagery intervention may be a suitable technique to study and establish the causal relationships between optimism and various cognitive, behavioral, and physical correlates.

\section{Acknowledgments}

This study was financed by a NWO grant (Dutch organization for scientific research) and carried out in cooperation with and facilitation by Maastricht University, the Netherlands.

\section{Appendix A}

Best possible self:

You have been randomly assigned to a condition in which you are going to think of your best possible self. Your best possible self means imagining yourself in a future in which everything has turned out as good as possible. You have worked hard and you have managed to realize all your life goals. You can envision it as satisfying all your life dreams and development of all your best possible potentials. In a moment, you are going to think of the best possible ways in which your life could develop on three domains (Personal, Relational, and Professional), with the goal to direct the decisions you make in the present. You have probably never thought about yourself in this way but research has indicated that this method may have a positive influence on your mood. We would like to encourage you to keep thinking about and imagine yourself in this way during the next two weeks. In order to determine and guide constructing your best possible self, for the next $20 \mathrm{~min}$ you are going to think of and write down your goals, skills and desires you would like to achieve in the far future for each of the three domains, and finally merge these into a personal story like a diary. Think during this whole process of realistic skills and manageable goals/wishes that you would like to possess or attain in the future.

\section{Personal domain}

Think of goals you would like to attain on the personal level (e.g. physical and psychological skills and developments).

\section{Professional domain}

Think of goals you would like to attain on the professional/workrelated level (e.g. position, accomplishments, level of expertise, but also occupation and skills, etc.).

\section{Relational domain}

Think of goals you would like to attain on the relational level (e.g. relations and contacts with loved ones, friends, colleagues, but also joint activities etc. in your social life).

Now we would like to ask you to write down in as much detail as possible your ideal future. You can use the goals you have just constructed as a guide. Like practiced in the previous imagery exercise, while describing your thoughts, try to activate your senses, feelings, and perceptions and make a personal story of it.

Daily activities:

You have been randomly assigned to a condition in which you are going to pay more attention to the daily activities of your life. This means you are going to give more thought to the ordinary daily activities of your life that normally would have gone unnoticed like for instance, specific meetings, lectures, conversations, typical thoughts you have during the day, etc. Use your day schedule of the past $24 \mathrm{~h}$ as guidance. This exercise will help you to more easily identify difficult problem areas you may have in your life and take action in order to improve these areas. You have probably never thought about yourself in this way but research has indicated that this method may have a positive influence on your mood. We would like to encourage you to keep thinking about and imagine yourself in this way during the next two weeks. In order to help you determine and guide your focus, work according to the following structure. Think of your day schedule of the past $24 \mathrm{~h}$ and go over it calmly. Think of the activities, meetings, etc. and go more deeply into the conversations, discussions, thoughts, or mood you may have had. For the next 15 min we would like to ask you to write down your thoughts. Like practiced in the previous imagery exercise, while describing your thoughts, try to activate your senses, feelings, and perceptions and make a personal story of it.

\section{References}

Andersson, G. (1996). The benefits of optimism: a meta-analytic review of the life orientation test. Personality and Individual Differences, 21(5), 719-725.

Argyle, M. (2001). The psychology of happiness (2nd ed.). New York, US: Routeledge.

Baron, R. M., \& Kenny, D. A. (1986). The moderator-mediator variable distinction in social psychological research: conceptual, strategic, and statistical considerations. Journal of Personality and Social Psychology, 51(6), 1173-1182.

Ben-Zur, H. (2002). Coping, affect and aging: the roles of mastery and self-esteem. Personality and Individual Differences, 32, 357-372.

Birley, J. A., Gillespie, N. A., Heath, A. C., Sullivan, P. F., Boomsma, D. I., \& Nicholas, G. M. (2006). Heritability and nineteen-year stability of long and short EPQ-R Neuroticism scales. Personality and Individual Differences, 40, 737-747.

Carver, C. S., \& Scheier, M. F. (1999). Optimism. In C. R. Snyder (Ed.), Coping: The psychology of what works (pp. 182-204). New York: Oxford University Press.

Cohen, L., van den Bout, J., Kramer, W., \& Vliet, T. (1986). A Dutch attributional style questionnaire: psychometric properties and findings of some Dutch-American differences. Cognitive Therapy and Research, 10(6), 665-669.

Eysenck, H. J., \& Eysenck, S. B. G. (1994). Manual of the Eysenck personality questionnaire. San Diego, CA: Educational and Industrial Testing Service.

Eysenck, H. J., Eysenck, S. B. G., \& Barrett, P. (1985). A revised version of the psychoticism scale. Personality and Individual Differences, 6, 21-29.

Fosnaugh, J., Geers, A. L., \& Wellman, J. A. (2009). Giving off a rosy glow: the manipulation of an optimistic orientation. The Journal of Social Psychology, 149 (3), 249-263.

Fredrickson, B. L. (2001). The role of positive emotions in positive psychology: the broaden-and-build theory of positive emotions. American Psychologist, 56, 218-226.

Fresco, D. M., Moore, M. T., Walt, L., \& Craighead, L. W. (2009). Self-administered optimism training: mechanisms of change in a minimally supervised psychoeducational intervention. Journal of Cognitive Psychotherapy, 23, 350-367.

Gibson, B., \& Sanbonmatsu, D. M. (2004). Optimism, pessimism, and gambling: the downside of optimism. Personality and Social Psychology Bulletin, 30, 149-160.

Gordon, R. A. (2008). Attributional style and athletic performance: strategic optimism and defensive pessimism. Psychology of Sport and Exercise, 9, 336-350.

Harrist, S., Carlozzi, B. L., McGovern, A. R., \& Harrist, A. W. (2007). Benefits of expressive writing and expressive talking about life goals. Journal of Research in Personality, 41, 923-930.

Holmes, E. A., Arntz, A., \& Smucker, M. R. (2007). Imagery rescripting in cognitive behaviour therapy: images, treatment techniques and outcomes. Journal of Behavior Therapy and Experimental Psychiatry, 38, 297-305.

Holmes, E. A., Coughtrey, A. E., \& Connor, A. (2008). Looking at or through rosetinted glasses? Imagery perspective and positive mood. Emotion, 8(6), 875-879.

Holmes, E. A., Mathews, A., Mackintosh, B., \& Dalgleish, T. (2008). The causal effect of mental imagery on emotion assessed using picture-word cues. Emotion, 8, 395-409.

King, A. (2001). The health benefits of writing about life goals. Personality and Social Psychology Bulletin, 27(7), 798-807. 
Kivimäki, M., Vahtera, J., Elovainio, M., Helenius, H., Singh-Manoux, A., \& Penti, J. (2005). Optimism and pessimism as predictors of change in health after death or onset of severe illness in family. Health Psychology, 24(4), 413-421.

Korrelboom, K., de Jong, M., Huijbrechts, I., \& Daansen, P. (2009). Competitive Memory Training (COMET) for treating low self-esteem in patients with eating disorders: a randomized clinical trial. Journal of Consulting and Clinical Psychology, 77(5), 974-980.

Lyubomirsky, S., Tkach, C., \& Dimatteo, M. R. (2006). What are the differences between happiness and self-esteem? Social Indicators Research, 78, 363-404.

Mackinnon, A., Jorm, A. F., Christensen, H., Korten, A. E., Jacomb, P. A., \& Rodgers, B. (1999). A short form of the positive and negative affect schedule: evaluation of factorial validity and invariance across demographic variables in a community sample. Personality and Individual Differences, 27, 405-416.

MacLeod, A. K. (1996). Affect, emotional disorder, and future-directed thinking. Cognition E Emotion, 10(1), 69-86.

Mahler, H. I. M., \& Kulik, J. A. (2000). Optimism, pessimism and recovery from coronary bypass surgery: prediction of affect, pain, and functional status. Psychology, Health \& Medicine, 5(4), 347-358.

Matthews, K. A., Raikkonen, K., Sutton-Tyrell, K., \& Kuller, L. H. (2004). Optimistic attitudes protect against progression of carotid atherosclerosis in healthy middle-aged women. Psychosomatic Medicine, 66, 640-644.

Peters, L. M., Flink, I. K., Boersma, K., \& Linton, S. J. (2010). Manipulating optimism: can imagining a best possible self be used to increase positive future expectancies? The Journal of Positive Psychology, 5(3), 204-211.

Peters, L. M., Sommer, M., Rijke de, J. M., Kessels, F., Heineman, E., Patijn, J., et al. (2007). Somatic and psychologic predictors of long-term unfavorable outcome after surgical intervention. Annals of Surgery, 245(3), 487-494.

Peterson, C., Semmel, A., von Baeyer, C., Abramson, L. Y., Metalsky, G. I., \& Seligman, M. E. P. (1982). The attributional style questionnaire. Cognitive Therapy and Research, 6, 287-299.

Peterson, C., \& Vaidya, R. S. (2001). Explanatory style, expectations, and depressive symptoms. Personality and Individual Differences, 31, 1217-1223.

Räikkönen, K., Matthews, K. A., Flory, J. D., Owens, J. F., \& Gump, B. B. (1999). Effects of optimism, pessimism, and trait anxiety on ambulatory blood pressure and mood during everyday life. Journal of Personality and Social Psychology, 76(1), 104-113.

Reilley, S. P., Geers, A. L., Lindsay, D. L., Deronde, L., \& Dember, W. N. (2005). Convergence and predictive validity in measures of optimism and pessimism: sequential studies. Current Psychology, 24, 43-59.

Riskind, J. H., Sarampote, C. S., \& Mercier, M. A. (1996). For every malady a sovereign cure: optimism training. Journal of Cognitive Psychotherapy: An International Quarterly, 10, 105-117.

Ruthig, J. C., Perry, R. P., Hall, N. C., \& Hladkyj, S. (2004). Optimism and attributional retraining: longitudinal effects on academic achievement, test anxiety, and voluntary course withdrawal. Journal of Applied Social Psychology, 34, 709-773.

Scheier, M. F., \& Carver, S. C. (1982). Self-consciousness, outcome expectancy, and persistence. Journal of Research in Personality, 16, 409-418.

Scheier, M. F., \& Carver, S. C. (1985). Optimism, coping, and health: assessment and implications of generalized outcome expectancies. Health Psychology, 4(3), 219-247.

Scheier, M. F., \& Carver, S. C. (1986). Dispositional optimism and physical wellbeing: the influence of generalized outcome expectancies on health. Journal of Personality, 55(2), 165-210.

Scheier, M. F., \& Carver, S. C. (1992). Effects of optimism on psychological and physical well-being: theoretical overview and empirical update. Cognitive Therapy and Research, 16, 210-228.

Scheier, M. F., Matthews, K. A., Owens, J. F., Schultz, R., Bridges, M. W. Magovern, G. J., \& Carver, C. S. (1999). Optimism and rehospitalization after coronary artery bypass graft surgery. Archives of Internal Medicine, 159(8), 829-834.

Segerstrom, S. C. (2001). Optimism, goal conflict, and stressor-related immune change. Journal of Behavioral Medicine, 24, 441-467.

Segerstrom, S. C. (2005). Optimism and immunity: do positive thoughts always lead to positive effects? Brain, Behavior, and Immunity, 19, 195-200.

Segerstrom, S. C. (2006). How does optimism suppress immunity? Evaluation of three affective pathways. Health Psychology, 25, 653-657.

Seligman, M. E. P. (1998). Learned optimism (2nd ed.). New York: Simon and Schuster

Seligman, M. E. P., Abramson, L. Y., Semmel, A., \& von Baeyer, C. (1979). Depressive attributional style. Journal of Abnormal Psychology, 88, 242-247.

Sheldon, K. M., \& Elliot, A. J. (1999). Goal striving, need-satisfaction, and longitudinal wellbeing: the self-concordance model. Journal of Personality and Social Psychology, 76, 482-497.

Sheldon, K. M., \& Lyubomirsky, S. (2006). How to increase and sustain positive emotion: the effects of expressing gratitude and visualizing best possible selves. Journal of Positive Psychology, 1, 73-82.

Solberg, N. L., Segerstrom, S. C., \& Septhon, S. E. (2005). Engagement and arousal: Optimism's effects during a brief stressor. Personality and Social Psychological Bulletin, 31(1), 111-120.

Tennen, H., \& Affleck, G. (1987). The costs and benefits of optimistic explanations and dispositional optimism. Journal of Personality, 55, 377-393.

Weinstein, N. D., \& Lyon, J. E. (1999). Mindset, optimistic bias about personal risk and health-protective behaviour. British Journal of Health Psychology, 4 289-300.

Wenglert, L., \& Rosen, A. S. (1995). Optimism, self-esteem, mood and subjective health. Personality and Individual Differences, 18(5), 653-661. 